\title{
Análise da dinâmica e dependência espaciais da produção de milho no território rural "Sertão Ocidental" sergipano
}

Analysis of spatial dynamics and dependence of maize production in the rural territory "Sertão Ocidental" of Sergipe

\author{
D. S. da Silva ${ }^{1 *}$; M. A. S. da Silva²; H. W. L. de Carvalho²; M. H. G. Dompieri ${ }^{3}$; \\ M. A. G. Cuenca ${ }^{2}$
}

${ }^{1}$ Departamento de Economia, Universidade Federal de Sergipe, 49100-000, São Cristóvão-SE, Brasil

${ }^{2}$ Embrapa Tabuleiros Costeiros, 49025-040, Aracaju-SE, Brasil

${ }^{3}$ Embrapa Territorial, 13070-115, Campinas-SP, Brasil

*damarissantos759@gmail.com

(Recebido em 17 de dezembro de 2018; aceito em 28 de agosto de 2019)

\begin{abstract}
O presente trabalho emprega análise exploratória espacial para investigar a dinâmica e a dependência espaciais da produção de milho no Território Rural Sertão Ocidental (TRSO) sergipano. Foram calculadas as autocorrelações espaciais global e local pelos índices Moran e LISA a partir das seguintes variáveis agregadas por município: área plantada (ha), quantidade produzida (t) e rendimento médio ( $\mathrm{kg} / \mathrm{ha}$ ) para o período de 1974 a 2016. Também foram analisados os baricentros para cada ano e variável de forma a identificar possíveis deslocamentos da produção. Conclui-se que houve deslocamento da produção e da área plantada no sentido do TRSO, e que rendimentos elevados sempre se mantiveram localizados no TRSO. Todas as três variáveis apresentaram forte dependência espacial demonstrada pela estatística $I$ de Moran, e heterogeneidade espacial local detectada pelo índice LISA, principalmente para a variável rendimento.

Palavras-chave: Índice de Moran, LISA, análise exploratória de dados espaciais, milho.

This study investigates the spatial dynamics and dependence of corn production in the area called "Sertão Ocidental" (TRSO), in Sergipe State, through the spatial exploratory analysis. Global and local spatial autocorrelations were calculated by the Moran and LISA indices from variables: planted area (ha), quantity produced (t) and average yield (kg/ha), from 1974 to 2016. Baricenters for each year and variable were analyzed in order to identify possible production shifts. It has been concluded that there was a shift of production and planted area towards TRSO, and that great yields always remained located in TRSO. All three variables showed strong spatial dependence demonstrated by I's Moran statistics, and local spatial heterogeneity detected by the LISA index, mainly for the yield variable.

Keywords: Moran index, LISA, exploratory spatial data analysis, maize.
\end{abstract}

\section{INTRODUÇÃO}

A modernização e o desenvolvimento de técnicas voltadas para a agricultura têm permitido maior produtividade e rentabilidade no campo. O melhoramento genético, com o desenvolvimento de sementes altamente produtivas e edafoclimaticamente adaptadas [1], o abandono progressivo de métodos rudimentares e a adoção de técnicas de maior eficiência como a mecanização têm permitido o desenvolvimento do agronegócio em torno da cultura do milho (grão) no Brasil [2]. Segundo o Levantamento Sistemático da Produção Agrícola - LSPA do IBGE [3], o milho é o terceiro produto agrícola mais produzido no Brasil, ultrapassado apenas pela soja e cana-de-açúcar. O país é o terceiro maior produtor mundial do grão [4].

Em Sergipe, o milho constitui-se num importante produto agrícola, visto que a área cultivada de culturas tradicionais como fava, mandioca e em especial o feijão sofreram um processo gradativo de substituição pelo plantio do grão [2].

Ao analisar a evolução da ocupação e utilização de áreas voltadas para a agricultura nos municípios sergipanos entre 2003 e 2012, Galina et al. (2014) [5] demonstram que a área plantada para o cultivo do milho tem progredido para os Territórios Rurais Sertão Ocidental (TRSO) e Alto 
Sertão (TRAS) sergipanos. Considerando 1990 a 2014 como período de análise, Cuenca et al. (2016) [2] confirmam que a área colhida e produtividade do milho se destacam nestes territórios.

Nogueira Junior et al. (2016) [6] reforçam que os municípios do Agreste sergipano expandiram de forma significativa sua área plantada, área colhida, produção e produtividade referente ao milho, contribuindo para a formação de um polo produtor da cultura no estado, corroborando com Cuenca et al. (2015) [7], que por meio de estudo a partir do modelo shiftshare, comprovam que a produção do milho acontece de forma sustentada, crescendo a uma taxa média de $18 \%$ a.a. entre 1990 e 2014, e, na análise comparativa com demais culturas, o milho desponta como mais produtivo.

Considerando como amostra o município sergipano de Carira, Cuenca et al. (2015) [7] apontam que a cultura do milho representava apenas $2 \%$ do PIB municipal em 1990, passando a corresponder a 49\% em 2010, alçando primeiro lugar em 2013 entre os maiores produtores do grão em Sergipe. De igual modo, Silva et al. (2015) [8] reiteram, mediante análise de autocorrelação espacial acerca dos principais produtos agrícolas cultivados na área de atuação da Embrapa Tabuleiros Costeiros que, em Sergipe, o milho coloca-se como um dos bens agrícolas mais importantes quando analisado seu rendimento médio entre os anos de 2011 e 2013.

Diversos fatores podem estar ligados à dinâmica produtiva agrícola. Raij (1983) [9] destaca o fator solo, confirmando que sua fertilidade exerce influência direta sobre o rendimento, visto que as propriedades físicas de um solo bem estruturado retêm e fornecem nutrientes as culturas. Fritsche -Neto e Môro (2015) [10] ressaltam que a escolha do cultivar representa, pelo menos, $50 \%$ da produtividade. Com o desenvolvimento de variedades de alto potencial genético, se observou maior controle a pragas, cujas sementes com adaptabilidade edafoclimática elevada, alavancaram a rentabilidade da produção. No entanto, por ser uma atividade que apresenta um risco relevante, a prática agrícola exige a presença de políticas públicas, e o ZARC (Zoneamento Agrícola de Risco Climático) derivado de estudos desenvolvidos pela Embrapa (Empresa Brasileira de Pesquisa Agropecuária) acerca do risco agrícola foi construído como instrumento de política agrícola e social, trazendo respaldo metodológico relativo à gestão do risco agrícola a fim de elevar o rendimento da lavoura e minimizar perdas observando clima, solo e cultivar; auxiliando produtores, agentes financeiros e consequentemente o consumidor [11].

Porém, ainda se acham hiatos entre a análise de alguma atividade produtiva e sua espacialização. Os efeitos da produção de determinado bem não respeitam fronteiras préestabelecidas, mas repercute em sua vizinhança. Almeida (2012) [12] ressalta que esse comportamento promove a formação de dependência espacial. O efeito transbordamento (spillover) movido pela atividade econômica e amparado pela proximidade geográfica será aqui observado para as variáveis área plantada, produção e rendimento médio.

Buscando averiguar tal dependência espacial, Saith e Kamitani (2016) [13] analisam o comportamento da agropecuária brasileira entre 1990 e 2013 e identificam, por meio de análise exploratória espacial, a ocorrência de autocorrelação nessa atividade entre microrregiões, mostrando que a produção migra do Sul e Sudeste para o Centro-Oeste e Norte do país, manifestando agregados espaciais, em especial, na região Norte. De igual modo, Rodrigues et al. (2012) [14] aderem a métodos de análise exploratória espacial para examinar o arranjo canavieiro paulista entre 1973 e 2007, concluindo que a atividade produtiva transcorre do Centro-Leste para o Oeste paulista, encontrando-se autocorrelação espacial no período analisado. A construção de suas análises mostra-se válida ao entendimento do comportamento de eventos espacialmente colocados, prestando assistência à formulação de políticas públicas.

A análise da dinâmica da atividade agropecuária brasileira também foi abordada por Holler et al. (2013) [15] e Garagorry et al. (2010) [16]. Os autores analisaram o deslocamento das atividades agropecuárias por meio do centro de massa de variáveis definidas, quantidade produzida para o efetivo de rebanho de gado de corte em Holler et al. (2013) [15] e produtos agroenergéticos em Garagorry et al. (2010) [16], ou seja os centros de massa municipais foram ponderados pela variável estudada.

Conclui-se que, embora se tenha a percepção do crescimento da atividade produtiva do milho no Território Rural Sertão Ocidental, nenhum estudo mensurou a dinâmica espacial (sentido e direção do crescimento da atividade) e a dependência espacial (autocorrelação espacial global e local) na região. Estudos econométricos espaciais recentes da atividade agropecuária demonstram 
a relevância deste tipo de investigação, mesmo que exploratória, para a compreensão do espaço agropecuário brasileiro.

Em vista disso, o presente artigo propõe-se a averiguar os aspectos da dinâmica e da dependência espaciais da produção do milho no Território Rural Sertão Ocidental (TRSO) sergipano, principal polo produtor do estado, observando como se dá o processo de deslocamento espacial de variáveis que são inerentes ao processo de cultivo (área plantada, quantidade produzida e rendimento médio), avaliando a hipótese de dependência espacial mediante análises dos índices de autocorrelação espacial global e local, Moran e LISA, respectivamente, para a série temporal definida.

\section{MATERIAL E MÉTODOS}

\section{1. Área de estudo}

Em Sergipe, a produção atual do milho se concentra no Território Rural Sertão Ocidental (TRSO), composto por 19 municípios, a saber: Lagarto, Poço Verde, Riachão do Dantas, Simão Dias, Tobias Barreto, Carira, Frei Paulo, Nossa Senhora Aparecida, Pedra Mole, Pinhão, Ribeirópolis, São Miguel do Aleixo, Areia Branca, Campo do Brito, Itabaiana, Macambira, Malhador, Moita Bonita e São Domingos, abrangendo uma área de $6.683,80 \mathrm{~km}^{2}$, colocando-se como um importante centro produtivo para o grão, em razão de sua produção transcorrer de forma consistente ao longo dos últimos dez anos. Além dos municípios do TRSO, foram incluídos ao estudo municípios adjacentes (até o $2^{\circ}$ vizinho) ao TRSO, como ilustra a Figura 1. Desta forma procura-se minimizar o efeito de borda nas análises de autocorrelação espacial, além de permitir a observação do deslocamento da produção para além do TRSO.

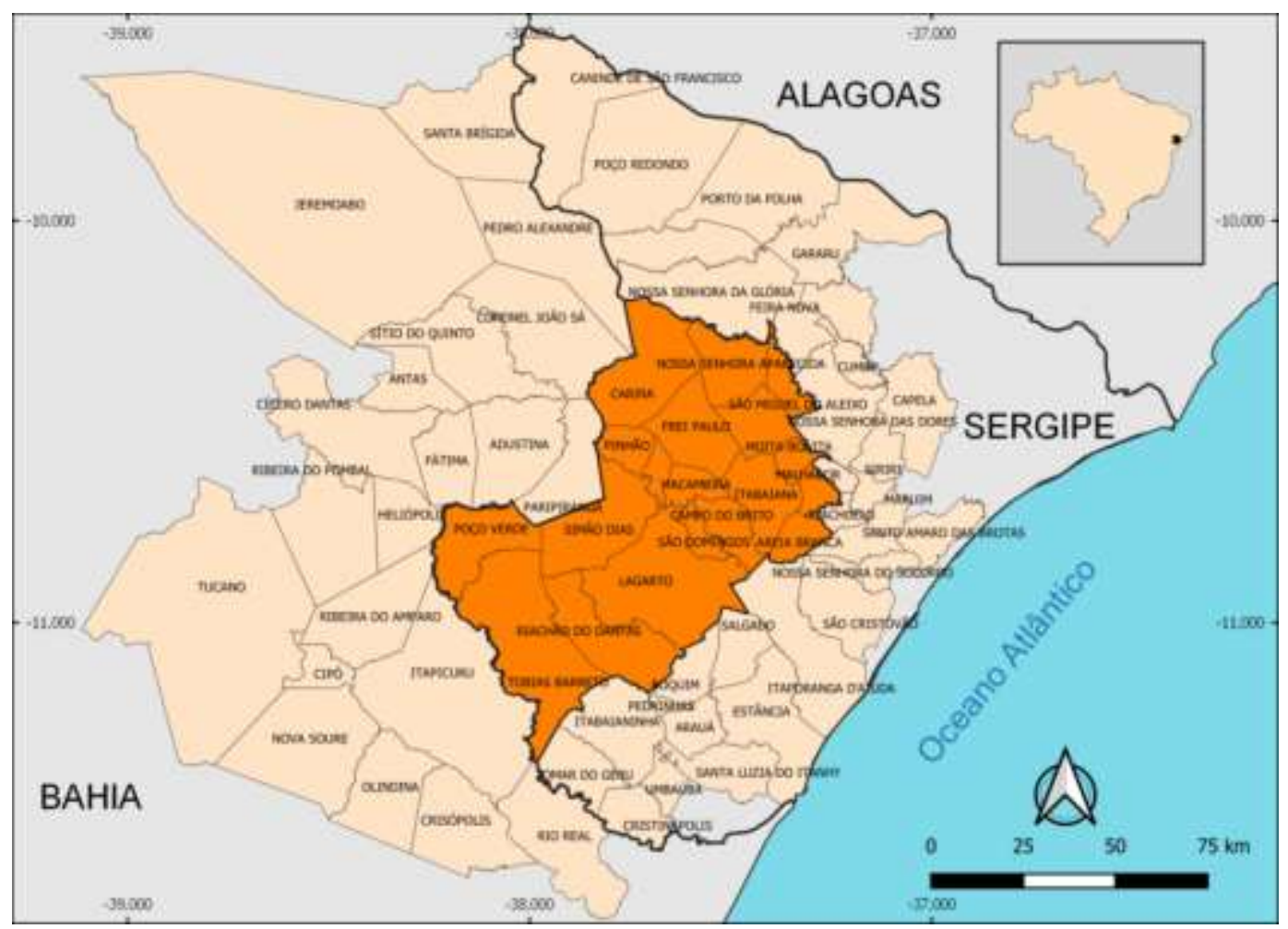

Figura 1: Localização dos municípios do TRSO e da área total de estudo que inclui os municípios vizinhos ( $2^{a}$ ordem) do Território. Fonte: Malha digital municipal 2014 do IBGE e Sistema de Informação Territorial do Ministério do Desenvolvimento Agrário. Fonte: Elaborado pelos autores. 


\subsection{Variáveis e estatística descritiva}

A fase inicial requereu coleta dos dados, adquiridos no Sistema IBGE de Recuperação Automática (SIDRA) a respeito da Produção Agrícola Municipal [17] para a cultura do milho, sobre: área plantada (em hectares), quantidade produzida (em tonelada) e rendimento (em quilograma por hectare), entre os anos de 1974 e 2016 para todos os municípios que abrangem a área em estudo. A série histórica dos dados foi analisada a partir de estatística descritiva, incluindo gráficos do tipo diagrama de caixa.

\subsection{Análises dos baricentros ou centros de massa}

A aquisição das malhas municipais nas bases do IBGE [18] para os estados de Sergipe e Bahia permitiu criar um Banco de Dados Geográfico da área de estudo e através destes localizar os baricentros das variáveis (médias das coordenadas planas ponderadas pelas variáveis de estudo) aqui consideradas a partir do Sistema de Coordenada Projetada WGS 1984 UTM Zone 24S, observando-se a formação de agregados pontuais e deslocamentos dos pontos centroides ao longo do tempo. Os baricentros, centros de massa, ponderados pelas respectivas variáveis foram calculados conforme Holler et al. (2013) [15].

\subsection{Análises de autocorrelação espacial}

A dependência espacial revela como os dados estão relacionados no espaço. E para atestar a dependência de uma área com respeito ao seu vizinho em função de uma determinada variável, são utilizados índices de autocorrelação espacial, que no nosso estudo é dado pelo índice I de Moran, nos conferindo a perspectiva global, e o índice de autocorrelação espacial local (LISA), para a perspectiva local.

Foram calculados os índices Moran e LISA para todas as variáveis, considerando somente os anos de 1988 a 2016, em razão de que para algumas delas não há dados disponíveis para os primeiros anos da série temporal, minorando o viés nas informações.

\subsubsection{Estatística $I$ de Moran}

A estatística $I$ de Moran é um coeficiente derivado da medida de autocovariância em produto cruzado. $O$ valor encontrado para $I$ deve ser igual ao valor esperado, considerando a significância estatística. Se o valor o valor encontrado superar I tem-se autocorrelação espacial positiva, mas se o valor encontrado for inferior a $I$ tem-se autocorrelação espacial negativa [19].

O índice é definido como:

$$
I=\frac{Z^{t} \cdot W_{Z}}{Z^{t} \cdot Z}
$$

Onde: $W_{z}$ é a matriz de pesos espaciais normalizada na linha;

$Z$ é dado pelo vetor dos valores padronizados da variável em questão, e;

$Z^{t}$ é dado pelo vetor transposto dos valores padronizados.

\subsection{2. Índice de autocorrelação espacial local}

No entanto, ao ponderarmos uma área mais ampla, admite-se a existência de lugares com relações de dependência espacial mais acentuada, diante disso, o índice LISA - Local Indicators of Spatial Association - propicia o panorama local, permitindo detectar a formação de pequenos aglomerados com dinâmica particular, como a construção de clusters.

O indicador de associação espacial local, isto é, o LISA, permite encontrar lugares que se isolam e se destacam em relação ao todo, mantendo relações de influência. Cressie (2015) [20] alega que este indicador deve possuir dois atributos: a) apresentar os conjuntos que expressam valores congêneres, e b) o somatório de cada valor local LISA deve corresponder ao valor global - Moran. 
Seguimos o índice apresentado na Equação (2):

$$
I_{i}=\frac{Z_{i} \cdot W_{z i}}{\sigma^{2}}
$$

Onde: $I_{i}$ representa o índice local para o município $i$;

$Z_{i}$ é o valor padronizado da variável em questão para o município $i$;

$W_{z i}$ é o valor médio das variáveis padronizadas para os municípios vizinhos a $i$, e; $\sigma^{2}$ é a variância da distribuição dos valores padronizados.

\subsubsection{Diagrama de dispersão de Moran}

Este diagrama busca segregar as unidades espaciais em grupos que correspondam ao seu respectivo grau de dependência ou influência, ou até mesmo identificar heterogeneidades, isto é, o nível de instabilidade espacial, como propõe Cressie (2015) [20]. Cada unidade é plotada ao seu quadrante correspondente.

Q1: a unidade observada e seu vizinho estão acima da média (grupo AA);

Q2: a unidade observada está abaixo e seu vizinho acima da média (grupo BA);

Q3: a unidade observada e seu vizinho estão abaixo da média (grupo BB) e;

Q4: a unidade observada está acima e seu vizinho abaixo da média (grupo AB).

\subsubsection{Mapas de Moran e LISA}

A fim de avaliar a autocorrelação espacial global, foram produzidos os Mapas de Moran, mensurando o nível de dependência espacial dentro da área em estudo. O esquema nos auxilia a formar categorias para cada variável, como retrata a Figura 2 [21].

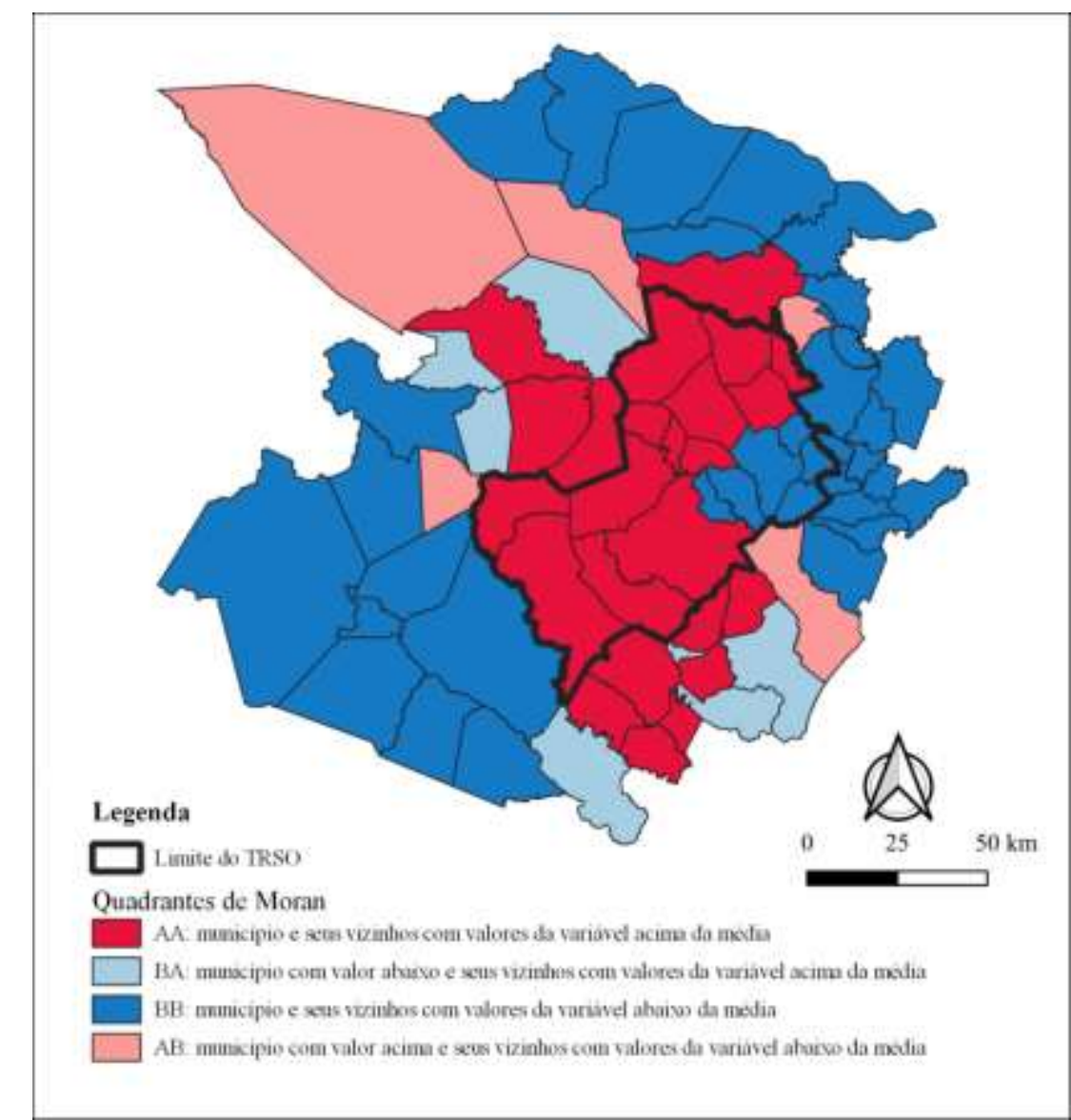

Figura 2: Exemplo de mapa coroplético onde os municípios são classificados segundo sua posição no mapa de Moran. Fonte: Malha digital municipal 2014 do IBGE e Sistema de Informação Territorial do Ministério do Desenvolvimento Agrário. Fonte: Elaborado pelos autores. 
Cressie (2015) [20] destaca, que o indicador local - LISA, pode manter concordância com o global - Moran, embora não sendo regra, havendo possiblidade de divergência. Aponta também que a estatística LISA admite alcançar porções, que, em meio ao todo, conservam maior dispersão em torno do valor médio, apresentando dinâmica diferenciada quanto ao identificado no agrupamento geral. Em vista disso, aderimos à classificação apresentada na Figura 3.

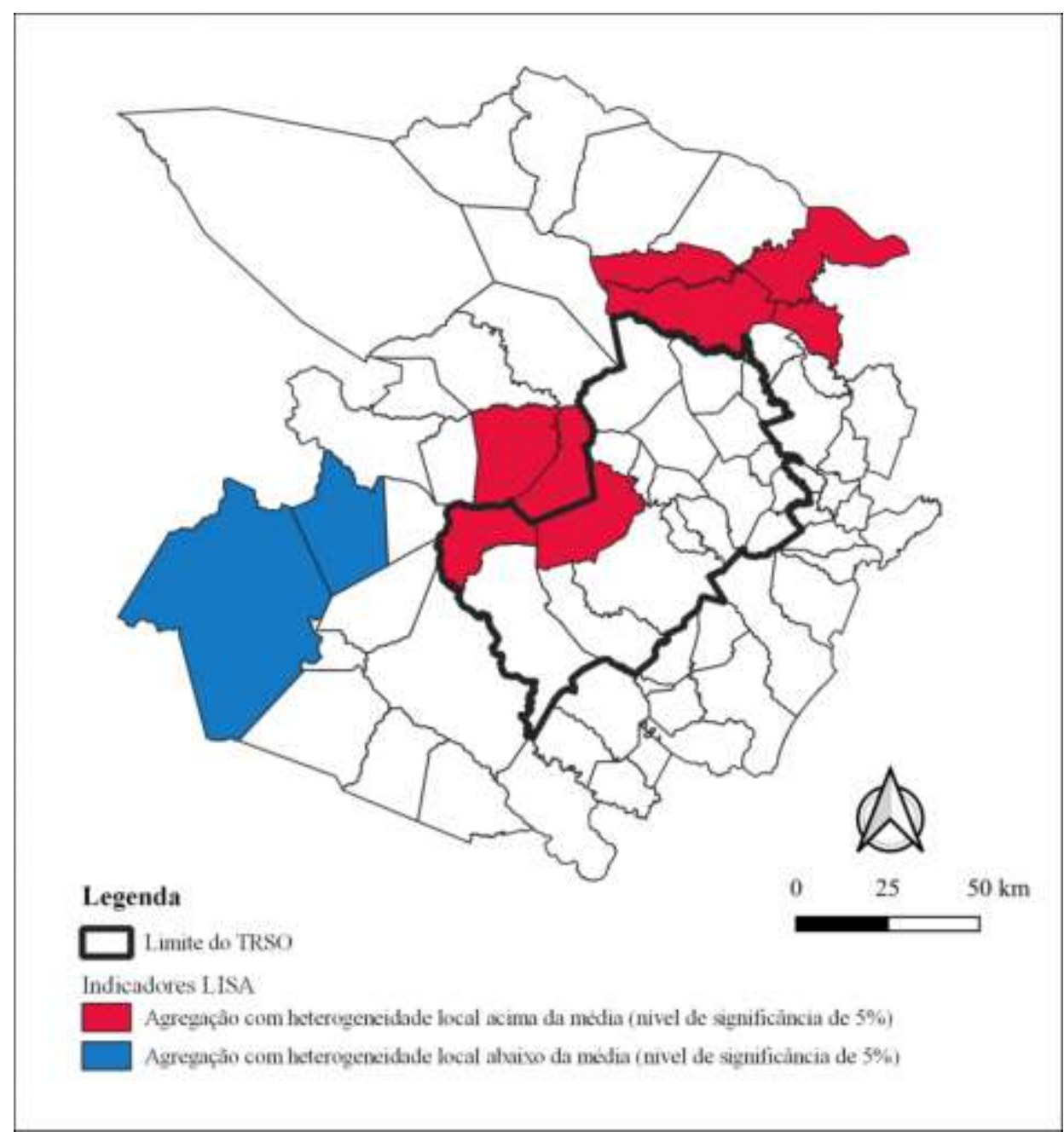

Figura 3: Exemplo de mapa coroplético onde os municípios são classificados conforme a existência de heterogeneidade local estatisticamente significante. Fonte: Malha digital municipal 2014 do IBGE e Sistema de Informação Territorial do Ministério do Desenvolvimento Agrário. Fonte: Elaborado pelos autores.

\subsection{Programas de computador utilizados}

Para construção da Base de Dados Geográficos do TRSO e geração dos mapas coropléticos foi utilizado o programa de computador Quantum GIS (QGIS) versão 3.0 [22]. As manipulações dos dados e as análises estatísticas foram conduzidas por meio do ambiente de programação $\mathrm{R}$ versão 1.0.153 [23]. Os cálculos de autocorrelação espacial foram feitos a partir do pacote $\mathrm{R}$ spdep e as manipulações de dados geográficos foram realizadas a partir do pacote $\mathrm{R}$ maptools.

\section{RESULTADOS E DISCUSSÃO}

\subsection{Estatística descritiva}

Primeiramente, foram analisados os valores médios das três variáveis para duas regiões: o Território Rural Sertão Ocidental e toda a região geral foco do estudo conforme Figura 1. Posteriormente, foram usados gráficos do tipo diagrama de caixa para avaliar a dispersão dos dados das três variáveis ao longo do tempo. 
Para a variável área plantada (ha), tem-se que os anos de 1990, 1993, 1998, 2001, 2004, 2008 e 2012 apresentaram queda da área plantada para a região geral estudada, com declínios mais acentuados em 1993 e 2012, mas que foram menos intensos no TRSO. Ademais, a velocidade de crescimento da área plantada média do TRSO se deu de forma mais célere, atingindo 5 mil $(h a)$, na área geral, e mais de 7000 (ha) no TRSO (Figura 4). Percebe-se que o TRSO se diferenciou da área geral estudada a partir de 2008 .

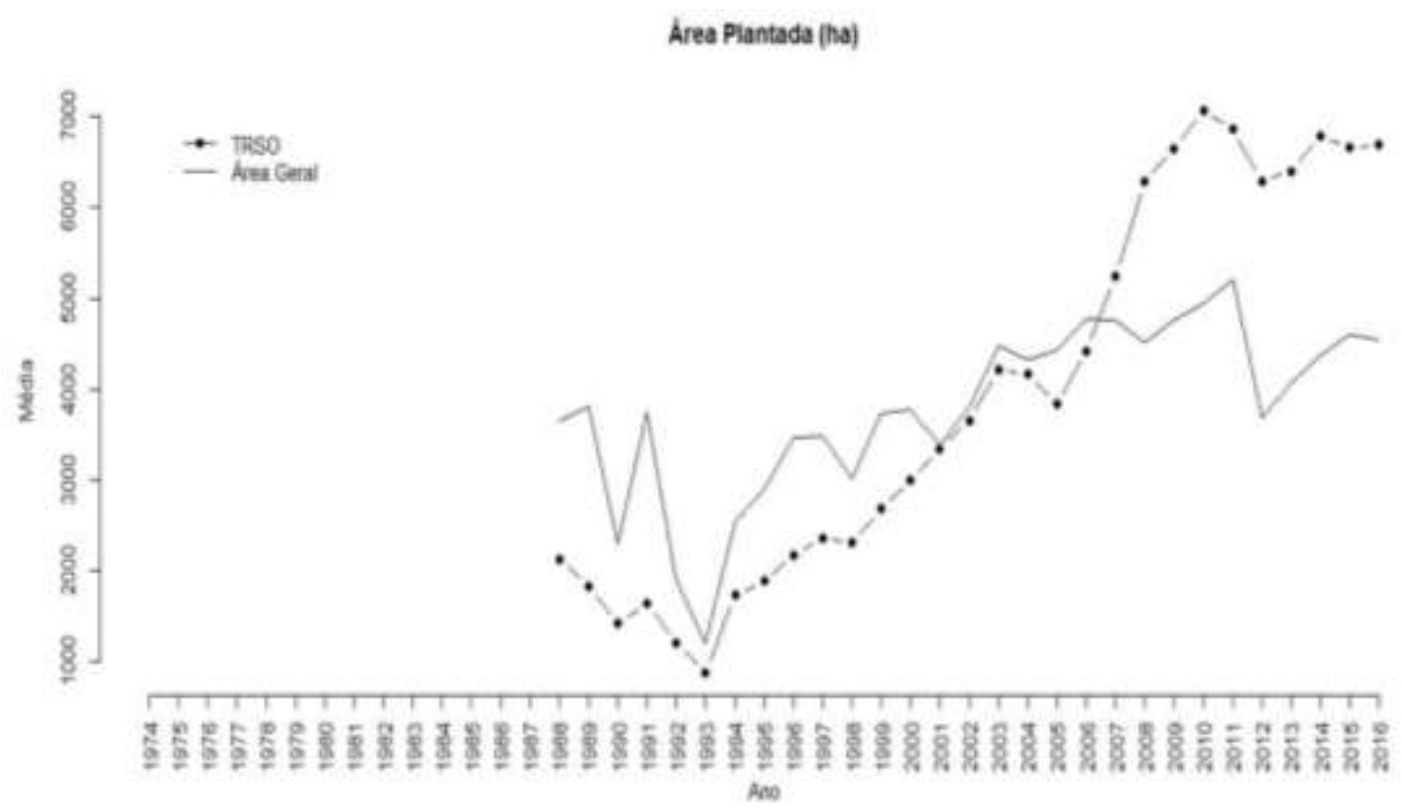

Figura 4: Distribuição média da área plantada (ha) para o TRSO e a área geral entre 1974-2016. Fonte: LSPA/IBGE. Fonte: Elaborado pelos autores.

Para a variável quantidade produzida $(t)$, tem-se que para a área geral, entre 1974 e 2000, a produção permaneceu abaixo de 5 mil $t$. No entanto, passou a ter crescimento contínuo a partir de 2001 , chegando ao maior volume produzido em 2010, em que ultrapassou as 15 mil $t$, com quedas abruptas em 2012 e 2016, ficando abaixo das 5mil t nesses anos. Para o TRSO houve um comportamento semelhante, mas com destaque para o volume médio máximo produzido, passando de 15 mil $t$ para 35 mil $t$ (Figura 5).

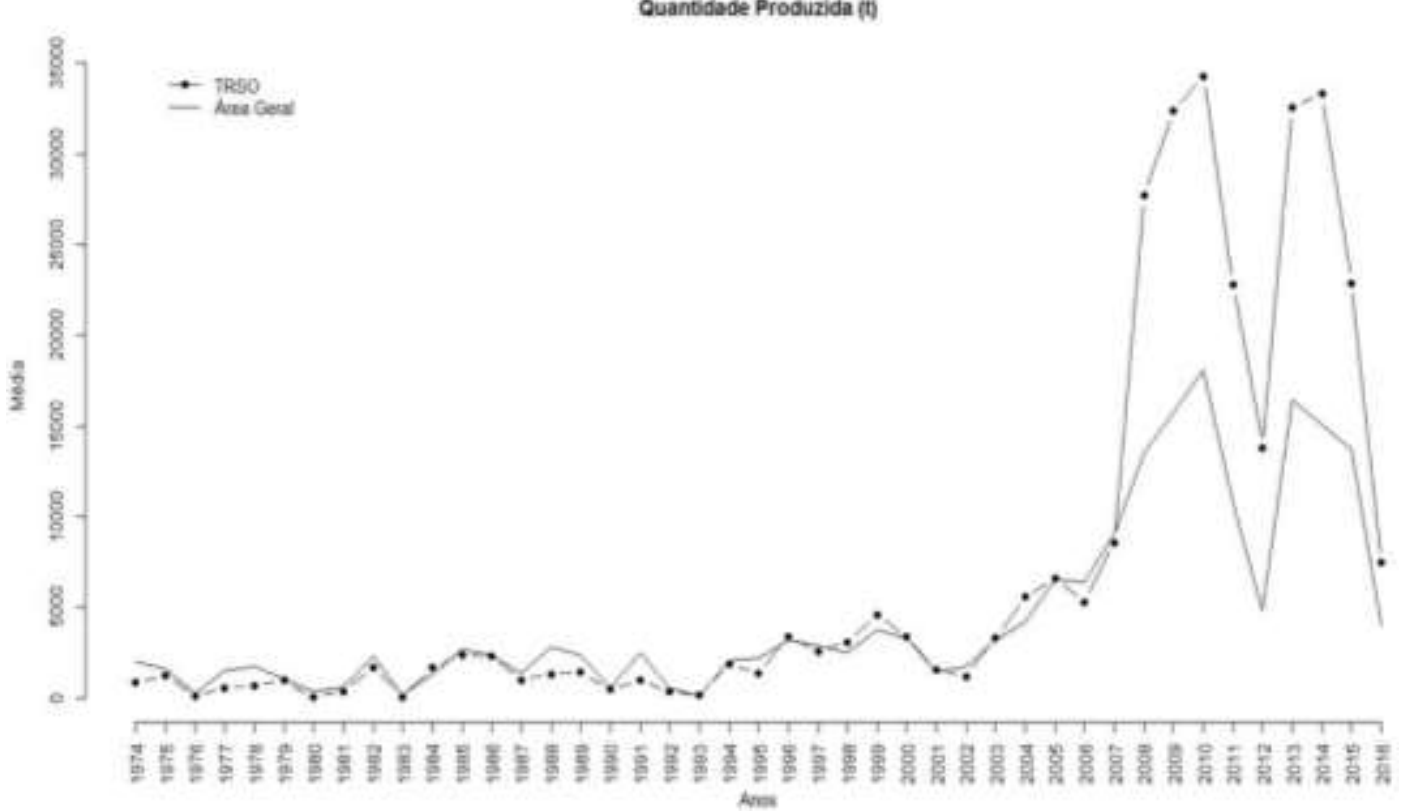

Figura 5: Distribuição média da quantidade produzida (t) para o TRSO e a área geral entre 1974-2016. Fonte: LSPA/IBGE.Fonte: Elaborado pelos autores. 
No TRSO o rendimento $(\mathrm{kg} / \mathrm{ha})$ foi superior a área geral desde 1993, embora se tenha observado oscilações. Nos anos de 2002, 2006, 2012 e 2016 observa-se forte queda no rendimento tanto para a área geral quanto para o TRSO (Figura 6).

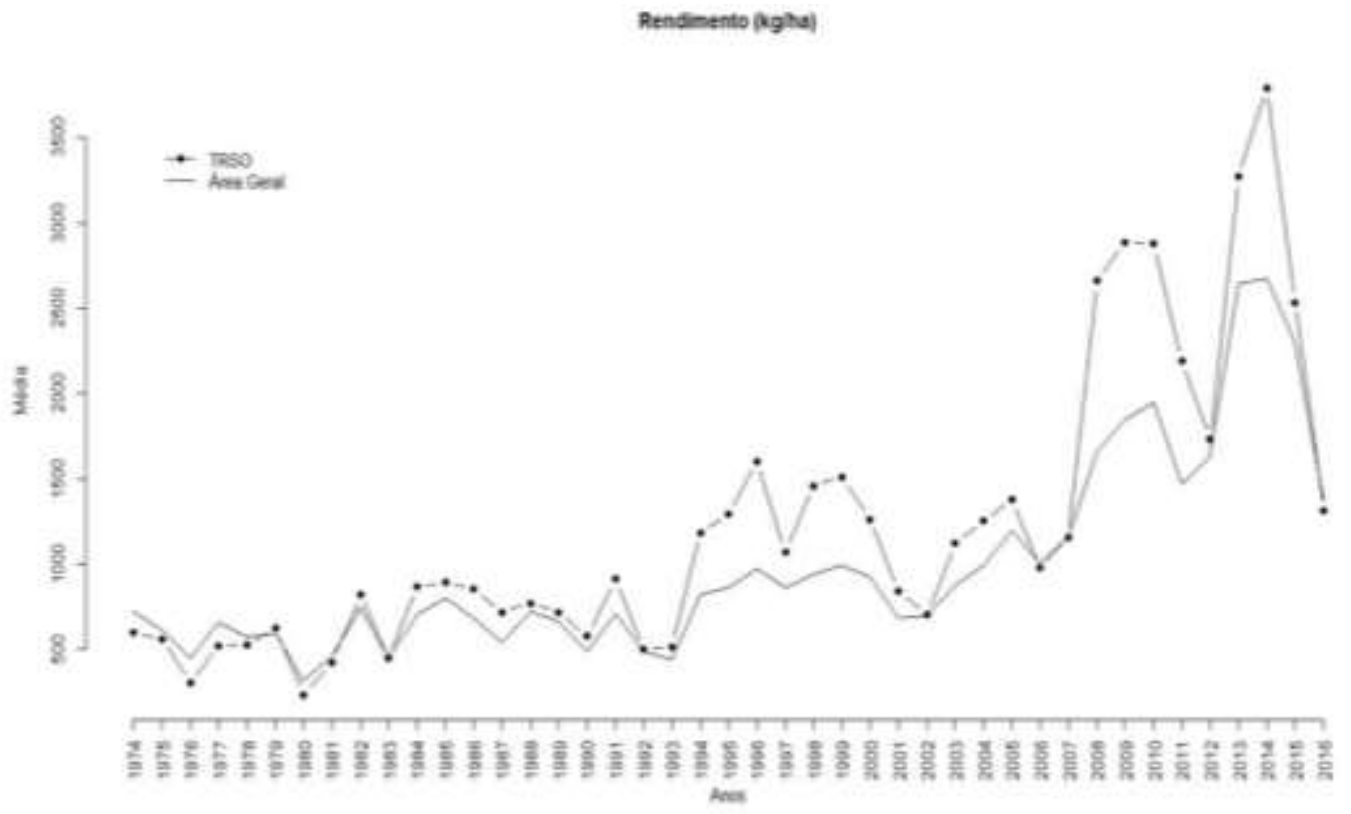

Figura 6: Distribuição média do rendimento ( $\mathrm{kg} / \mathrm{ha}$ ) para o TRSO e a área geral entre 1974-2016. Fonte: LSPA/IBGE. Fonte:Elaborado pelos autores.

Destaca-se que, para o TRSO, entre 2003 e 2007, não houve presença de dados atípicos da área plantada; em 2016 encontramos a maior dispersão nos dados, com um limite superior alto e sem dados atípicos (Figura 7). Similarmente, para a variável quantidade produzida, os dados encontram-se agrupados, começando a variar a partir de 2008, mas regredindo em 2012 e 2016 (Figura 8). Para a variável rendimento se observou uma maior dispersão dos dados, sobretudo a partir de 2008, com destaque para o ano de 2014, com maior amplitude de toda a série temporal (Figura 9).
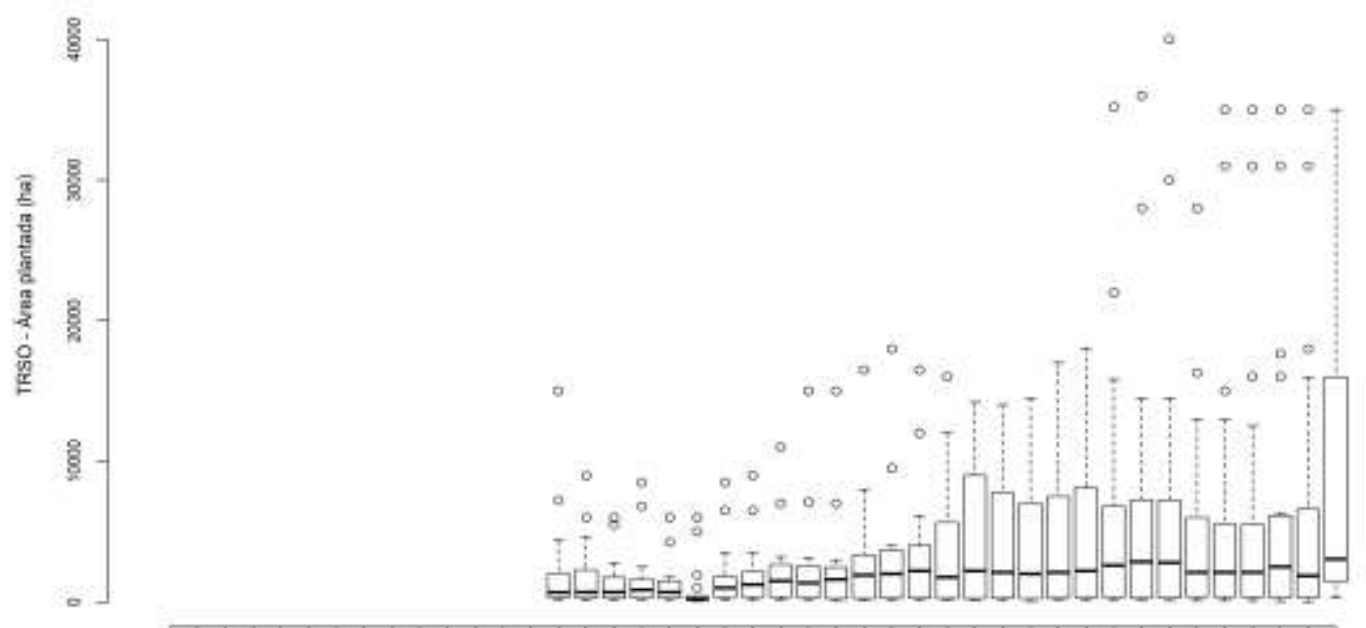

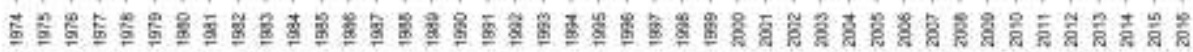
Ano

Figura 7: Diagrama de caixa para a área plantada (ha) no TRSO entre 1974-2016. Fonte: PAM/IBGE. Fonte: Elaborado pelos autores. 

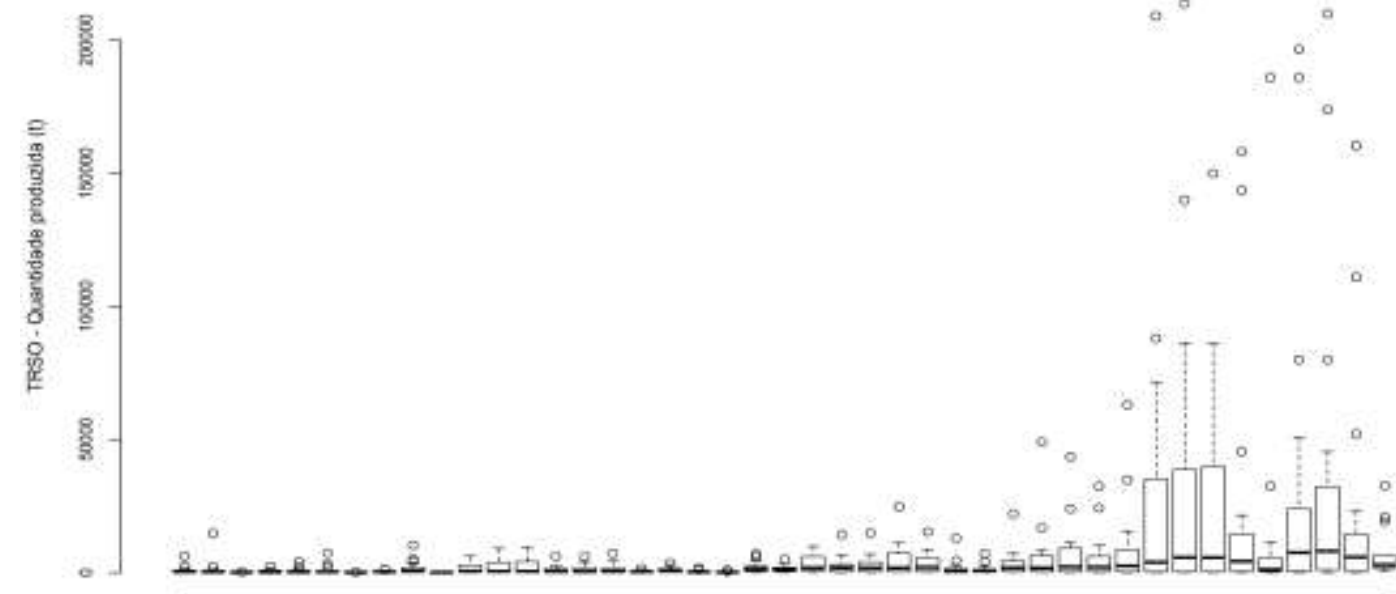

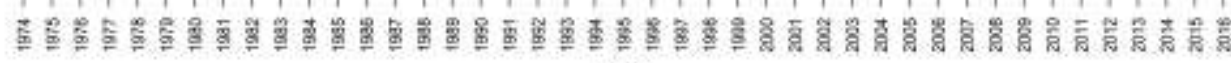

Ano

Figura 8: Diagrama de caixa para a quantidade produzida (t) no TRSO entre 1974-2016. Fonte: LSPA/IBGE. Elaborado pelos autores.

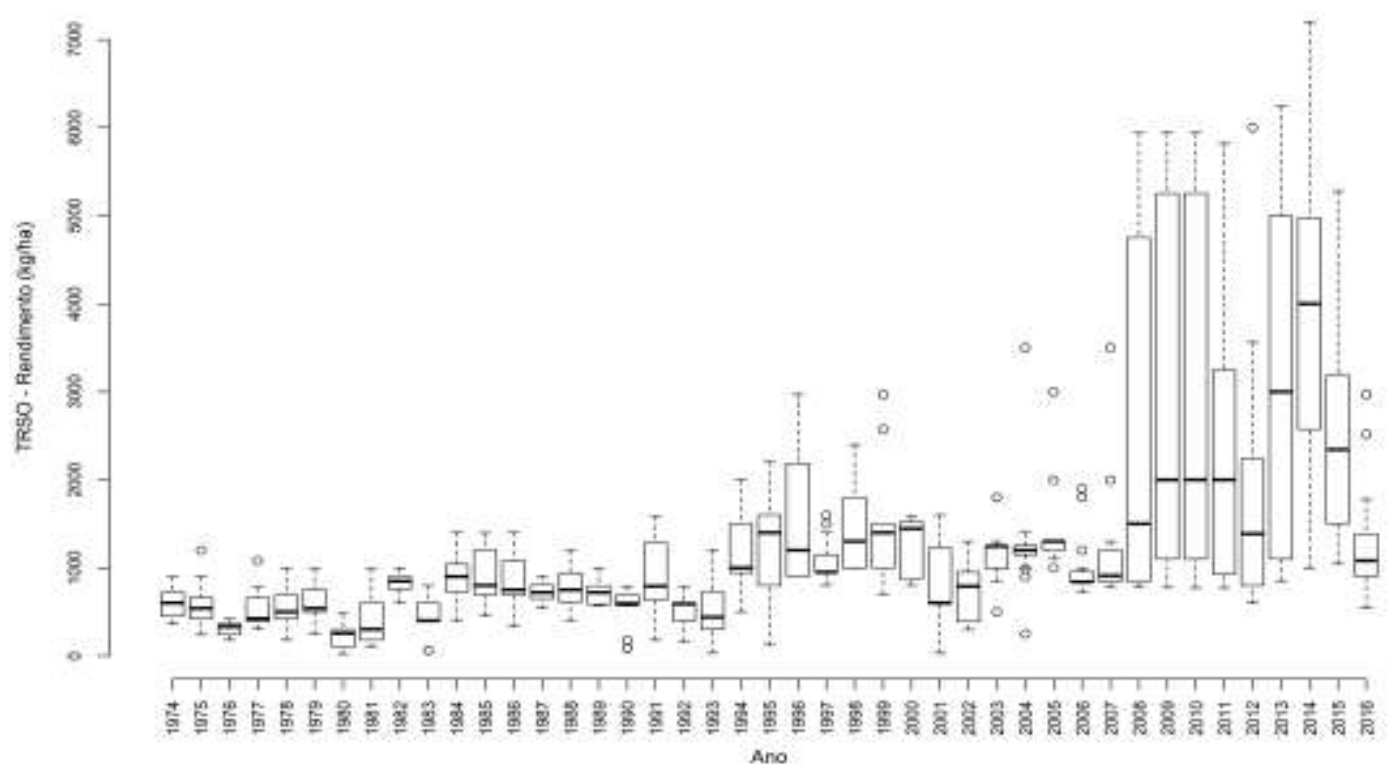

Figura 9: Diagrama de caixa para o rendimento médio ( $\mathrm{kg} / \mathrm{ha})$ no TRSO entre 1974-2016. Fonte: LSPA/IBGE. Elaborado pelos autores.

Pode-se concluir da análise estatística descritiva que houve crescimento quase que linear da área plantada no TRSO, que a partir de 2008 o TRSO começou a se diferenciar da área geral estudada principalmente quanto ao rendimento, que os anos de 2012 e 2016 foram anos críticos para a produção de milho em função das secas prolongadas, com quedas nas áreas plantadas, produção e rendimento. 


\subsection{Baricentros}

Observa-se na Figura 10 que todos os baricentros ponderados pela variável área plantada (ha) encontram-se fora do TRSO, concentrando-se em apenas três municípios, a saber: Fátima, Adustina e Paripiranga, todos no estado da Bahia. Entre 1991 e 1994 houve grandes deslocamentos dos baricentros, do município de Fátima em direção ao município de Adustina. Entre 2006 e 2012, os baricentros continuam rumo ao sentido Leste, chegando ao município de Paripiranga, recuando de 2013 a 2016, encerrando o período na fronteira nordeste do município de Adustina.

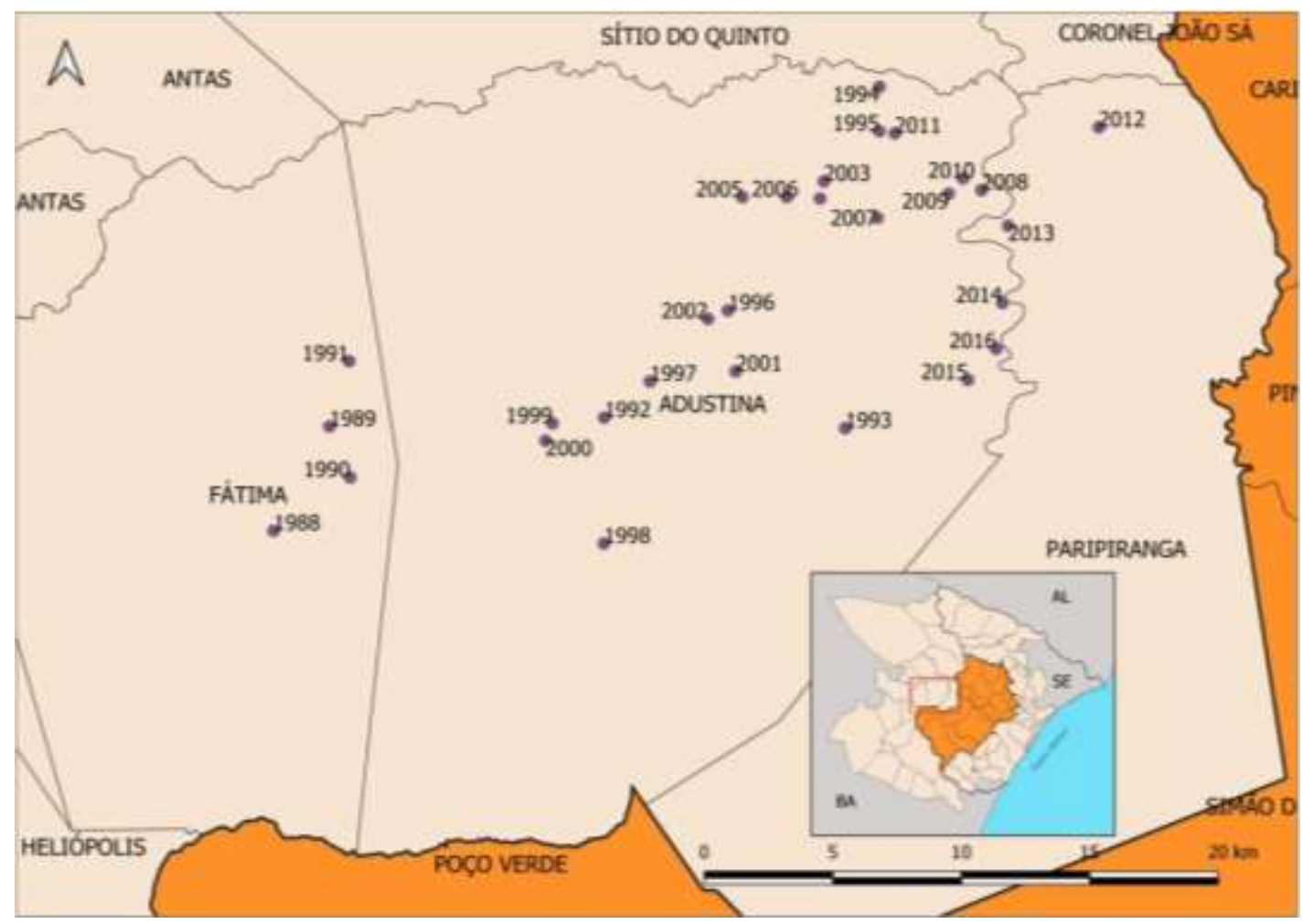

Figura 10: Baricentros para a variável área plantada (ha) entre 1988-2016. Fonte: Malha digital municipal 2014 do IBGE, Sistema de Informação Territorial do Ministério do Desenvolvimento Agrário e dados tabulares da Pesquisa Agrícola Municipal do IBGE. Fonte:Elaborado pelos autores.

Na Figura 11 tem-se os baricentros ponderados pela variável quantidade produzida $(t)$. Entre 1975 e 1984 houve grandes deslocamentos, exceto 1982. O município de Adustina conservou o maior número de baricentros, os quais continuaram a convergir ao Leste. 


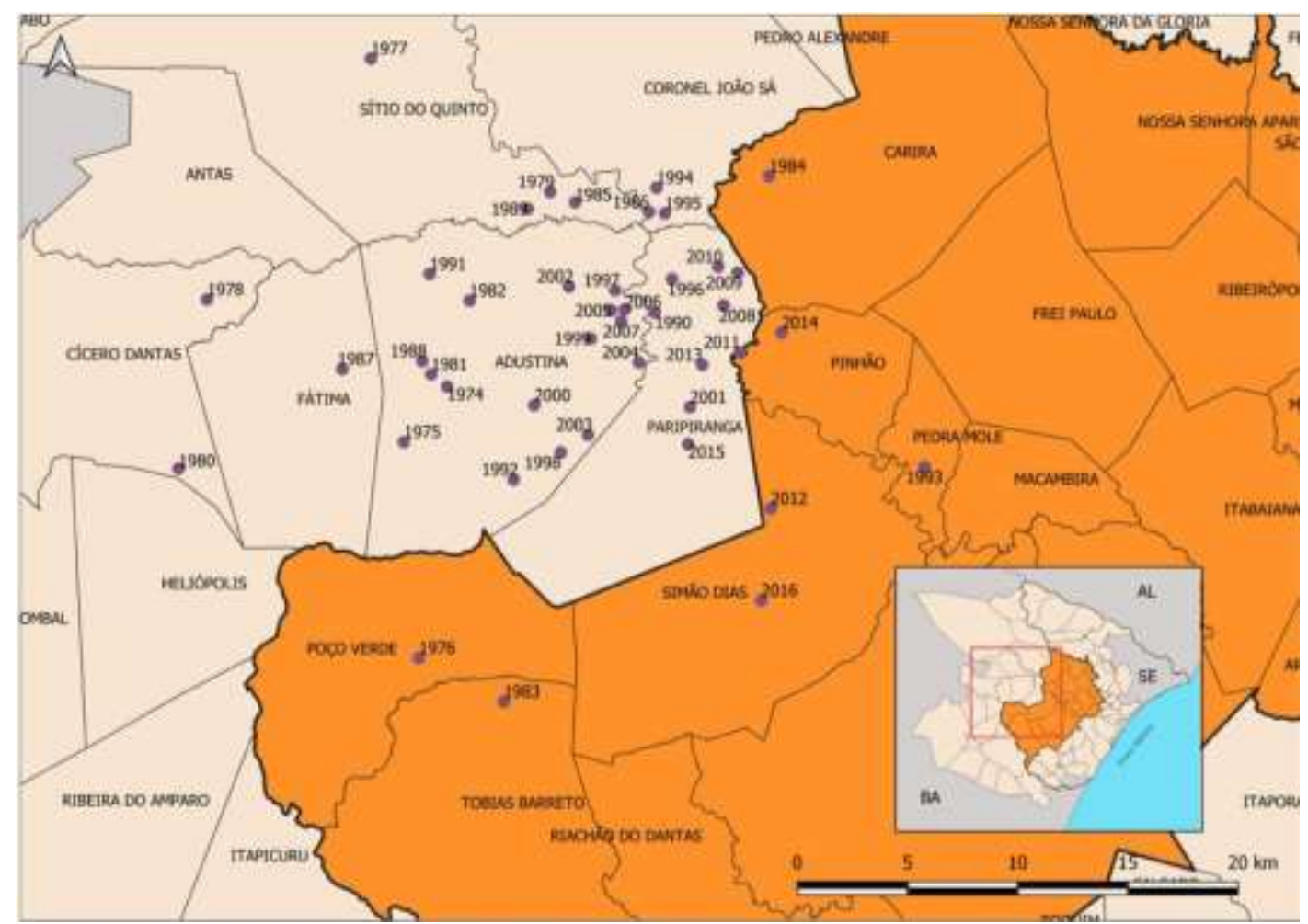

Figura 11: Baricentros para a variável quantidade produzida (t) entre 1974-2016. Fonte: Malha digital municipal 2014 do IBGE, Sistema de Informação Territorial do Ministério do Desenvolvimento Agrário e dados tabulares da Pesquisa Agrícola Municipal do IBGE. Fonte:Elaborado pelos autores.

Os baricentros ponderados pela variável rendimento médio $(\mathrm{kg} / \mathrm{ha})$ se mantêm dentro do TRSO (Figura 12), em sua totalidade. Conclui-se que a área plantada e produção estão se deslocando na direção Oeste-Leste, e que o Território Rural Sertão Ocidental se destacou quanto a variável rendimento. 


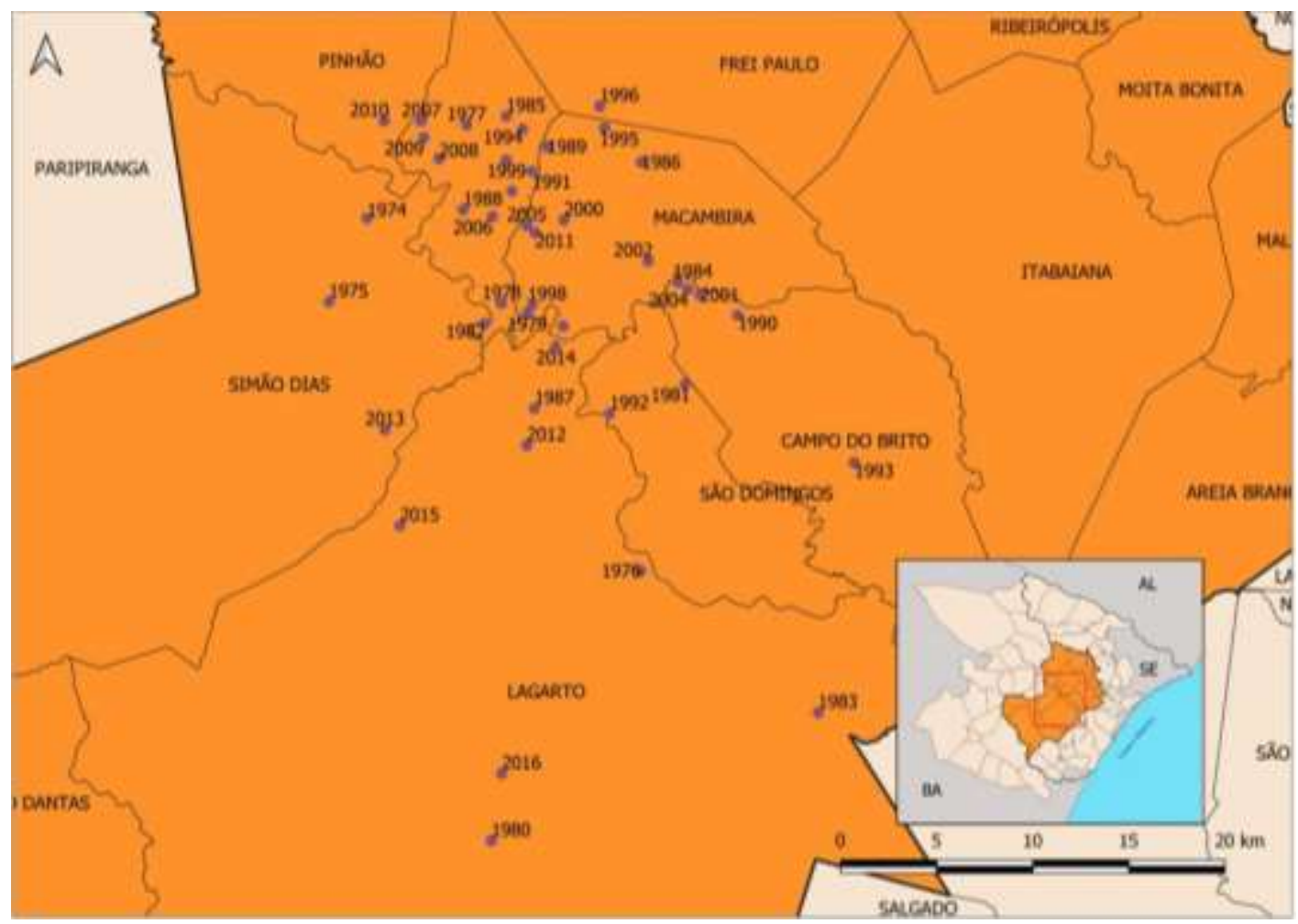

Figura 12: Baricentros para a variável rendimento médio $(\mathrm{kg} / \mathrm{ha}$ ) entre 1974-2016. Fonte: Malha digital municipal 2014 do IBGE, Sistema de Informação Territorial do Ministério do Desenvolvimento Agrário e dados tabulares da Pesquisa Agrícola Municipal do IBGE. Fonte:Elaborado pelos autores.

\subsection{Autocorrelação espacial}

\subsubsection{Mapa de Moran}

Para a variável área plantada, tem-se que no TRSO, entre os anos de 1988 e 1999, apenas os municípios de Poço Verde e Simão Dias se integravam ao grupo AA de forma contínua (Figura 13). No entanto, entre 2000 e 2016, os municípios de Pinhão, Carira, Nossa Senhora Aparecida e Frei Paulo foram se inserindo ao grupo, formando na fronteira Oeste um forte agregado de municípios com área plantada acima da média de toda a região estudada. Observa-se também pouca variação no padrão espacial a partir do mapa de Moran.

Para a variável quantidade produzida, tem-se grande variação tanto com relação ao número quanto à localização espacial dos municípios que compõem o grupo AA (Figura 14). Entre 1988 e 1997, exceto 1993, esses municípios se concentravam na região Oeste da área geral em estudo. Após esse período, sua concentração aconteceu entre o Oeste da região geral e a área central em estudo, o TRSO. Quanto ao TRSO, novamente destacamos os municípios de Poço Verde, Simão Dias, Pinhão, Carira, Nossa Senhora Aparecida e Frei Paulo como municípios positivamente autocorrelacionados.

A variável rendimento reuniu as maiores variações na distribuição espacial a partir do mapa de Moran (Figura 15). O conglomerado de municípios positivamente autocorrelacionados, isto é, pertencentes ao grupo AA migra em várias direções dentro da região geral estudada, sinalizando que fatores, além dos edafoclimáticos, interferem no rendimento da região. Todavia, em toda a série temporal, o TRSO abrigou grande parte dos municípios altamente produtivos quanto à cultura do milho (grupo AA), ressalvando as atipicidades em 2001 e 2016. A presença regular de autocorrelação positiva no TRSO convergiu com a análise dos baricentros, pois o TRSO abrigou todos os pontos centroides. Destaca-se o ano de 2014, que atingiu os maiores índices para todas as variáveis. 


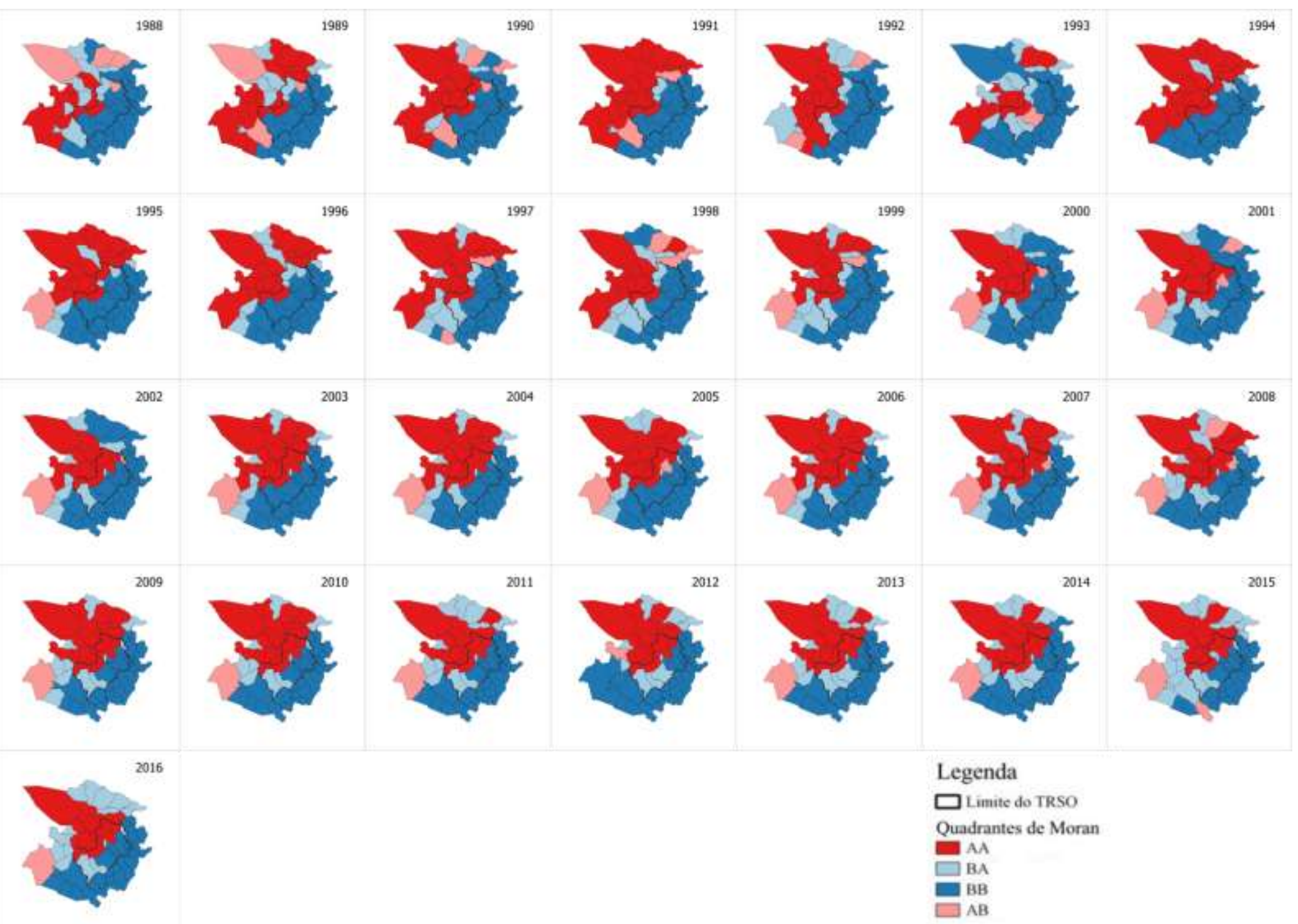

Figura 13: Mapa de Moran para a variável área plantada (ha) entre 1988-2016. Fonte: Malha digital municipal 2014 do IBGE, Sistema de Informação Territorial do Ministério do Desenvolvimento Agrário e dados tabulares da Pesquisa Agrícola Municipal do IBGE. Fonte:Elaborado pelos autores. 

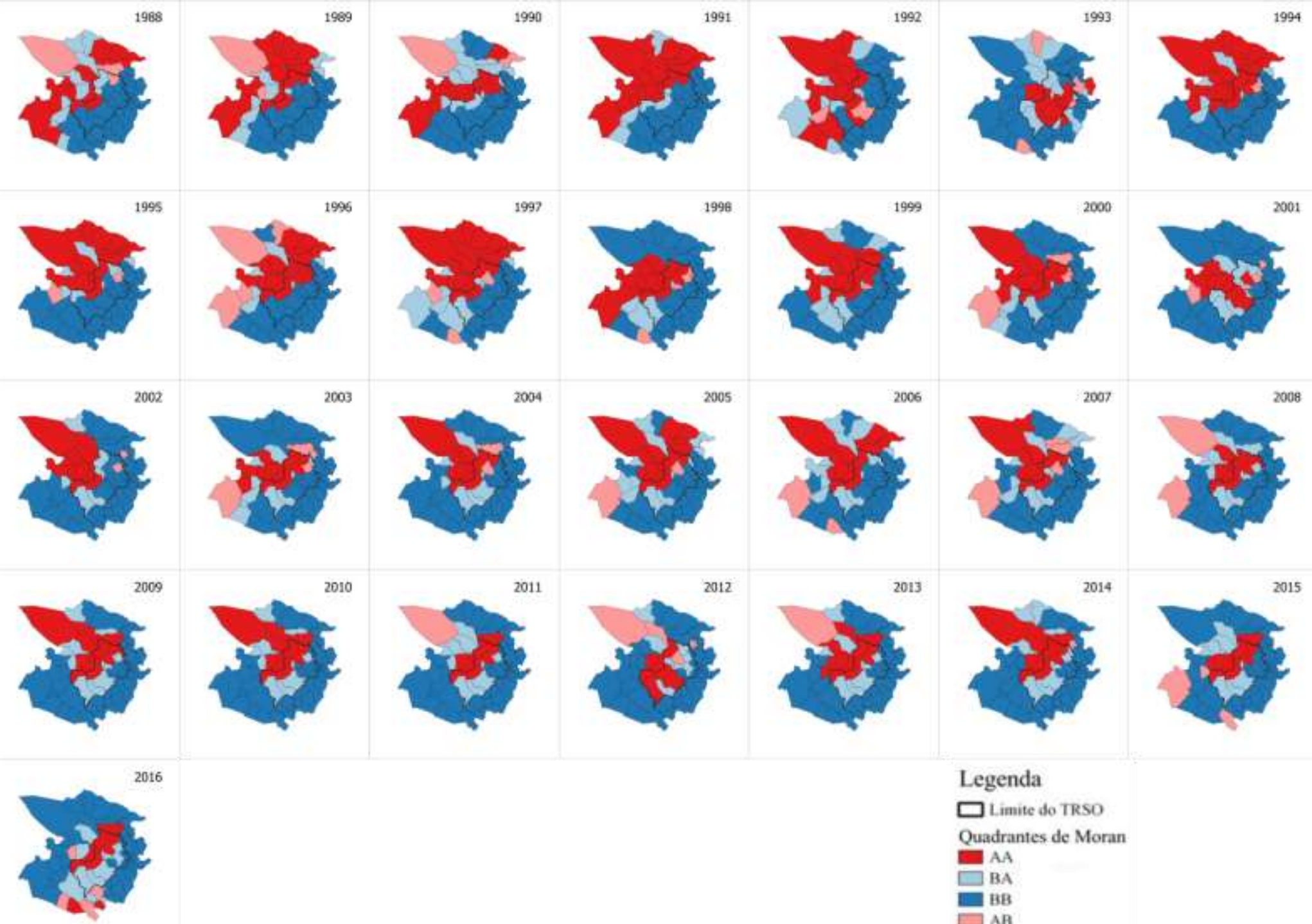

$$
\begin{aligned}
& \text { Legenda } \\
& \square \text { Limite do TRSO } \\
& \text { Quadrantes de Moran } \\
& \text { AA } \\
& \text { BA } \\
& \text { BB }
\end{aligned}
$$

Figura 14: Mapa de Moran para a variável quantidade produzida (t) entre 1988-2016. Fonte: Malha digital municipal 2014 do IBGE, Sistema de Informação Territorial do Ministério do Desenvolvimento Agrário e dados tabulares da Pesquisa Agrícola Municipal do IBGE. Fonte:Elaborado pelos autores. 


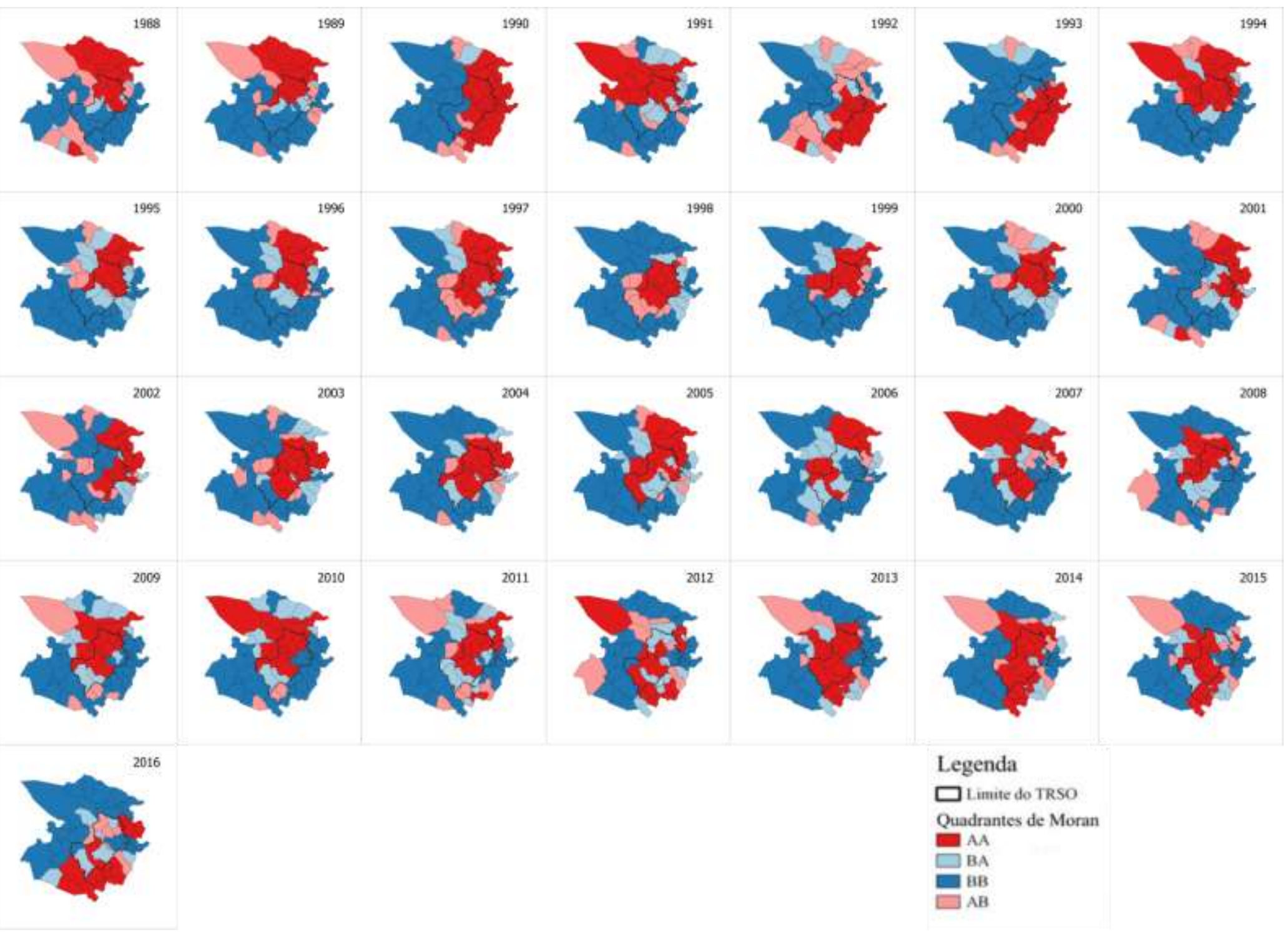

Figura 14: Mapa de Moran para a variável rendimento médio (kg/ha) entre 1988-2016. Fonte: Malha digital municipal 2014 do IBGE, Sistema de Informação Territorial do Ministério do Desenvolvimento Agrário e dados tabulares da Pesquisa Agrícola Municipal do IBGE. Fonte: Elaborado pelos autores. 


\subsubsection{MAPA DE LISA}

Na Figura 16 temos a indicação de heterogeneidade espacial anual para a variável área plantada. Observa-se que os agregados locais positivamente autocorrelacionados se deslocaram do Sudoeste da área geral em estudo rumo ao centro da região. Os municípios baianos de Fátima, Adustina e Paripiranga sobressaíram-se ao longo da série temporal. Quanto ao TRSO, destacamos o município de Poço Verde e os municípios de Simão Dias e Carira a partir de 2007.

Quando se observa a variável quantidade produzida, tem-se que, assim como para a área plantada (ha), essa variável também apresentou heterogeneidade espacial para a série temporal (Figura 17). A partir de 1990 observa-se que os municípios com volume produzido fortemente relevante se encontram no centro da região geral estudada, fronteiriço, quando não imerso, ao TRSO. Mais uma vez destacamos os municípios baianos de Fátima, Adustina e Paripiranga, e os municípios sergipanos de Poço Verde, Simão Dias e Carira.

Semelhante ao Mapa de Moran, o Mapa de LISA para o rendimento ( $\mathrm{kg} / \mathrm{ha})$, apresentou grande variação da localidade da heterogeneidade espacial (Figura 18). Todavia, percebemos que com exceção dos anos 1988, 2004, 2012 e 2016, todos os demais agregados locais positivos se tangenciaram ou se inseriram no TRSO. Novamente colocamos em destaque o ano de 2014, que atingiu o ponto máximo de rendimento na região, no entanto, com diversos grupos de menor relevância produtiva em seu entorno. 


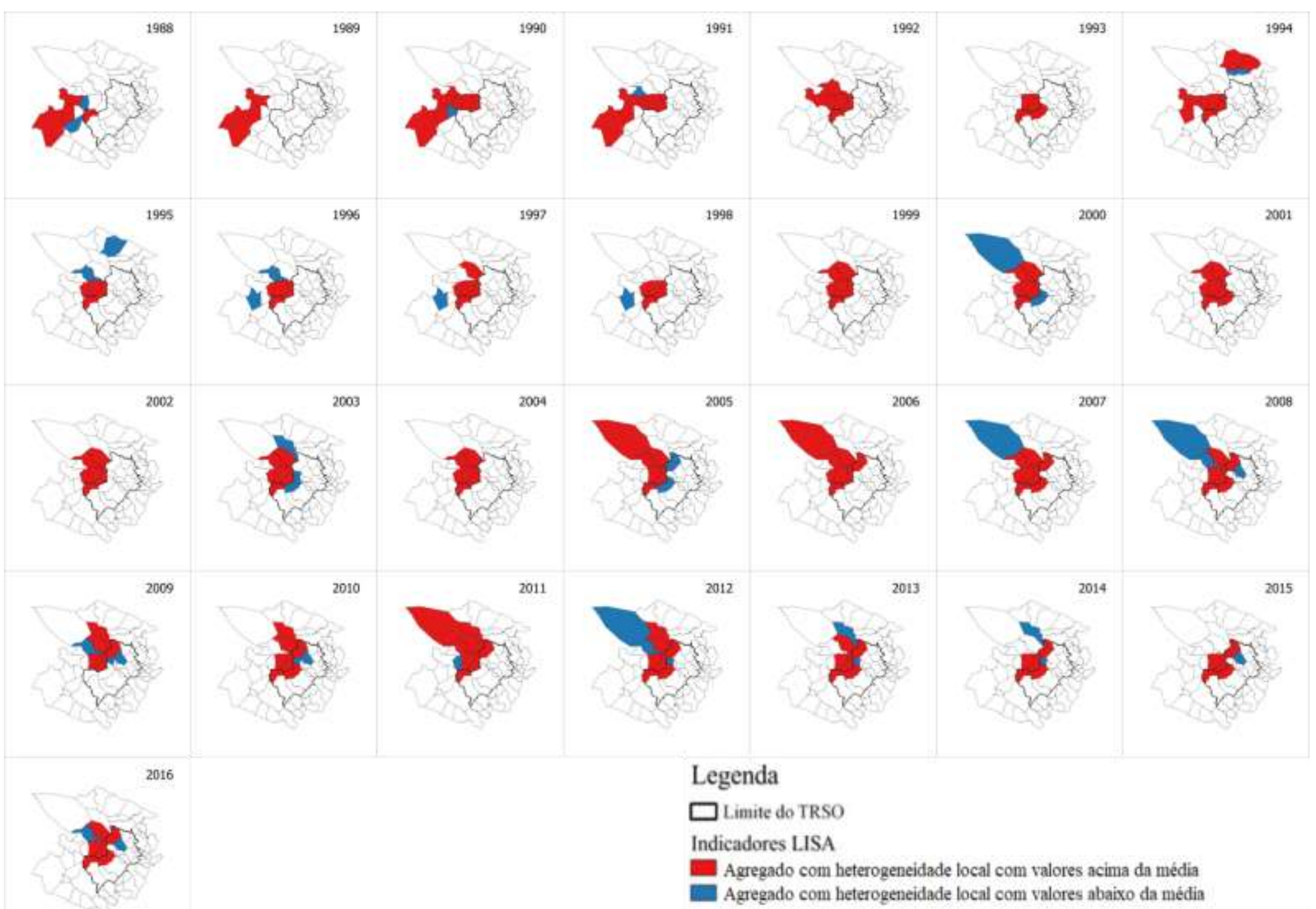

Figura 15: Mapa de Lisa para a variável área plantada (ha) entre 1988-2016. Fonte: Malha digital municipal 2014 do IBGE, Sistema de Informação Territorial do Ministério do Desenvolvimento Agrário e dados tabulares da Pesquisa Agrícola Municipal do IBGE. Fonte: Elaborado pelos autores. 


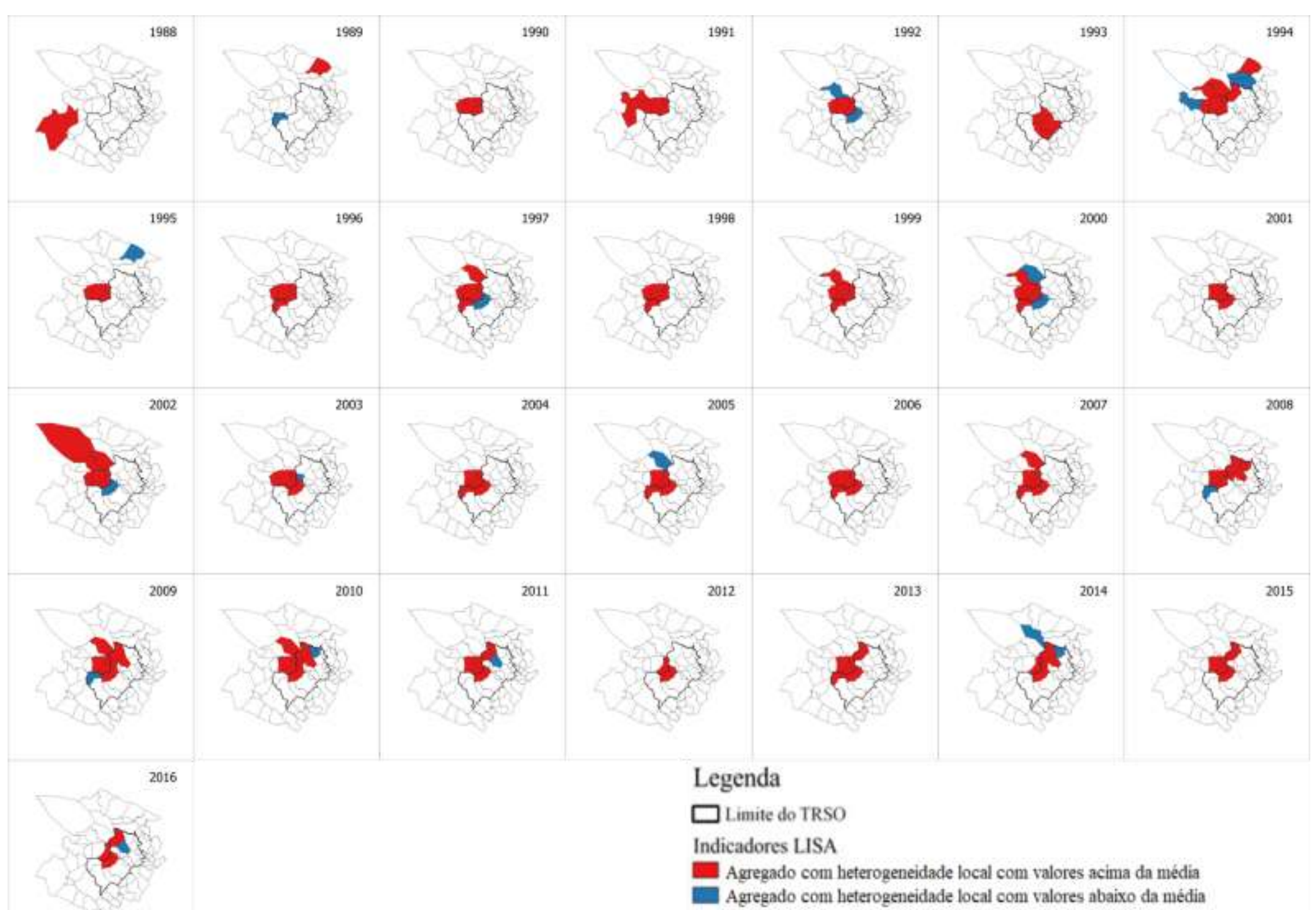

Figura 17: Mapa de Lisa para a variável quantidade produzida (t) entre 1988-2016. Fonte: Malha digital municipal 2014 do IBGE, Sistema de Informação Territorial do Ministério do Desenvolvimento Agrário e dados tabulares da Pesquisa Agrícola Municipal do IBGE. Fonte: Elaborado pelos autores. 


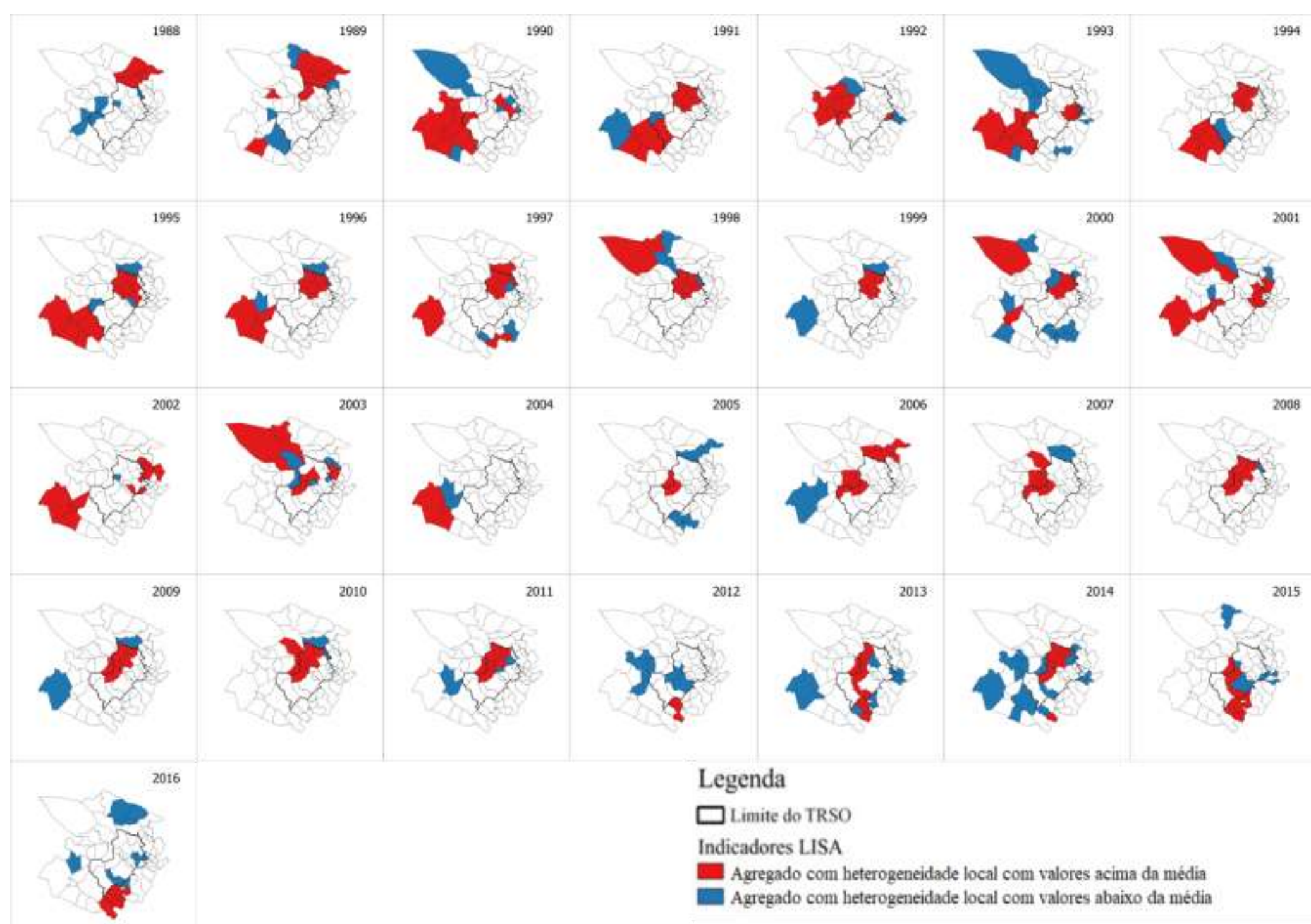

Figura 18: Mapa de Lisa para a variável rendimento médio (kg/ha) entre 1988-2016. Fonte: Malha digital municipal 2014 do IBGE, Sistema de Informação Territorial do Ministério do Desenvolvimento Agrário e dados tabulares da Pesquisa Agrícola Municipal do IBGE. Fonte: Elaborado pelos autores. 


\subsection{3. Índice global de Moran}

A partir dos índices globais de Moran, podem-se identificar os períodos que ocorrem maior ou menor dependência espacial entre os municípios da região estudada para as variáveis estudadas (Tabela 1).

A variável área plantada (ha) agrega-se espacialmente com maior força entre os anos de 1996 e 2003. Nos primeiros anos, observa-se maior autocorrelação espacial nos municípios mais ao Oeste da região total estudada, destacando-se os municípios baianos de Adustina e Paripiranga e abrangendo poucos municípios do TRSO. No entanto, ao longo do tempo, a há um deslocamento para os municípios do agreste e alto sertão sergipanos, sentido Leste. Entre 2003 e 2016, observase o enfraquecimento dessa dependência espacial, permanecendo com valores de autocorrelação espacial elevados nos municípios com grande área plantada, mas não acompanhados pelos municípios vizinhos.

Para a variável quantidade produzida (t), a autocorrelação espacial foi marcada por grandes oscilações, ou seja, várias permutas entre momentos de maior e menor dependência espacial, somente no curto período entre 2004 e 2007 há um comportamento de forte agregação espacial moderada.

Os mapas de Moran e os de LISA também mostraram certa variação espacial dos agregados locais para a variável rendimento, denotando que outros fatores além das condições edafoclimáticas interferiram no rendimento da produção de milho. Destaca-se também que o TRSO se mostrou a região com os maiores rendimentos, tanto pelas análises dos baricentros quanto pelos mapas de Moran e LISA. Ainda sobre a variável rendimento, no ano de 1994 houve um pico de forte autocorrelação espacial mais ao Norte da região em análise. Entre 1994 e 2004, começou uma fase de enfraquecimento dessa dependência espacial do rendimento médio, em que os municípios com os maiores rendimentos médios se dispersaram dentro da região geral investigada.

Entre 2004 e 2005, houve uma interrupção da tendência de aumento da autocorrelação espacial positiva para a variável rendimento, retomada no ano de 2010. Para esta variável, as fases de queda, estagnação e em seguida de forte crescimento podem estar ligadas a fatores como o acesso a crédito, redes de solidariedade, fornecedores de insumos, disponibilidade de mão-de-obra e existência de associações colaborativas. Quanto ao rendimento destacam-se os municípios sergipanos vizinhos e contíguos de Frei Paulo, Carira, Simão Dias, Poço Verde e Pinhão.

Em 2012 houve uma nova queda da autocorrelação espacial positiva, certamente induzida pela intensa seca que atingiu o Nordeste brasileiro, verificando-se o maior grau de fragmentação de todo o período analisado. Em seguida, a região voltou a agregar-se espacialmente, convergindo ao TRSO.

Com base nos resultados, rejeita-se a hipótese nula de não correlação espacial entre os municípios da área estudada a partir das variáveis área plantada, quantidade produzida e rendimento, considerando o índice de significância de 5\%. 
Tabela 1: Valores para os índices I de Moran para as três variáveis estudadas e para cada ano da série temporal. Fonte:Elaborado pelos autores.

\begin{tabular}{|c|c|c|c|}
\hline Ano & Área plantada & Quantidade produzida & Rendimento \\
\hline 1988 & $0,3387 * * *$ & $0,1565^{* *}$ & $0,3943 * * *$ \\
\hline 1989 & $0,3660 * * *$ & $0,2293 * * *$ & $0,5988 * * *$ \\
\hline 1990 & $0,4646 * * *$ & $0,2714 * * *$ & $0,5992 * * *$ \\
\hline 1991 & $0,4351 * * *$ & $0,3718 * * *$ & 0,4916 *** \\
\hline 1992 & $0,4990 * * *$ & $0,3023 * * *$ & $0,4350 * * *$ \\
\hline 1993 & $0,2828 * * *$ & $0,1381^{*}$ & $0,5707 * * *$ \\
\hline 1994 & $0,5066 * * *$ & $0,5104 * * *$ & $0,6347 * * *$ \\
\hline 1995 & $0,4375 * * *$ & $0,3481 * * *$ & $0,6476 * * *$ \\
\hline 1996 & 0,3578 *** & $0,3380 * * *$ & $0,6398 * * *$ \\
\hline 1997 & $0,4078 * * *$ & $0,4348 * * *$ & $0,5283 * * *$ \\
\hline 1998 & $0,3881 * * *$ & $0,4263 * * *$ & $0,5688 * * *$ \\
\hline 1999 & $0,4285^{* * *}$ & $0,5191 * * *$ & $0,5151 * * *$ \\
\hline 2000 & $0,4479 * * *$ & $0,4242 * * *$ & $0,5178 * * *$ \\
\hline 2001 & $0,4904 * * *$ & $0,2305 * * *$ & $0,4419 * * *$ \\
\hline 2002 & $0,5168 * * *$ & $0,4561 * * *$ & $0,4856 * * *$ \\
\hline 2003 & 0,5676 *** & $0,3073 * * *$ & $0,4412 * * *$ \\
\hline 2004 & $0,5290 * * *$ & $0,3607 * * *$ & $0,1489 * *$ \\
\hline 2005 & $0,4980 * * *$ & $0,3636 * * *$ & $0,1533 * *$ \\
\hline 2006 & $0,5176 * * *$ & $0,3531 * * *$ & $0,3224 * * *$ \\
\hline 2007 & $0,5379 * * *$ & $0,3508 * * *$ & $0,4085^{* * *}$ \\
\hline 2008 & $0,4945 * * *$ & $0,3364 * * *$ & $0,5153 * * *$ \\
\hline 2009 & $0,5076 * * *$ & $0,3823 * * *$ & $0,6062 * * *$ \\
\hline 2010 & $0,5043 * * *$ & $0,4412 * * *$ & $0,6427 * * *$ \\
\hline 2011 & $0,5318 * * *$ & $0,2668 * * *$ & $0,4746 * * *$ \\
\hline 2012 & $0,4489 * * *$ & $0,0407^{*}$ & $0,1924 * *$ \\
\hline 2013 & $0,4478 * * *$ & $0,3338 * * *$ & $0,4647 * * *$ \\
\hline 2014 & $0,4164 * * *$ & $0,3348 * * *$ & $0,5461 * * *$ \\
\hline 2015 & $0,3877 * * *$ & $0,2782 * * *$ & $0,4150 * * *$ \\
\hline 2016 & $0,4524 * * *$ & $0,2476 * * *$ & $0,4538 * * *$ \\
\hline
\end{tabular}

* Nível de significância de 5\%.

** Nível de significância de $1 \%$.

*** Nível de significância de $0,1 \%$.

\section{CONCLUSÃO}

Conclui-se que houve deslocamento da produção e da área plantada no sentido do TRSO, e que o rendimento sempre se manteve localizado no TRSO. Todas as três variáveis apresentaram forte dependência espacial demonstrada pela estatística $I$ de Moran, e heterogeneidade espacial local detectada pelo índice LISA, principalmente para a variável rendimento.

As análises sinalizaram que dentro da área total investigada, o TRSO concentrou o circuito produtivo, cuja dinâmica de produção para a cultura do milho converteu-se em um novo patamar a partir de 2008. Levanta-se, por hipótese, que fatores como o Zoneamento Agrícola de Risco Climático (ZARC) para o grão no sertão de Sergipe tenha tido influência neste processo de modernização dos sistemas de produção. Em 2004 tem-se a primeira publicação de uma portaria para o zoneamento agrícola de risco climático para o milho no ano de 2004, que incluiu eventos de sensibilização dos produtores nos primeiros anos até a completa compreensão e uso deste instrumento público de ordenamento territorial pelos agentes produtivos da cadeia do milho na região, incluindo agentes de crédito.

Concomitante ao ZARC tem-se a influência do milho híbrido na região, material de alto potencial genético, que entra em uso comercial no Brasil a partir de 2007, impactando nos níveis 
de produção, sobretudo na produtividade, contribuindo para uma forte mudança no sistema de produção do milho no TRSO.

Por fim, indica-se que a qualidade do solo na região tenha induzido, de igual modo, a produtividade. Como exemplo, todo o norte do município de Simão Dias, município destaque dentro das análises de dependência e heterogeneidade espaciais, é classificado como cambissolo háplico, com grande oferta de nutrientes e de menor risco a erosão, permitindo alcançar níveis de produtividade acima da média regional.

A expansão demonstrada no sentido Oeste-Leste da monocultura do milho na região de estudo implicou na substituição de outras culturas como a mandioca e o fumo, no forte impacto nos níveis de susceptibilidade à erosão e de desertificação, e no incremento da dinâmica dos sistemas socioeconômicos ligados ao setor agrícola. Assim, espera-se que este estudo forneça subsídios para elaboração de políticas públicas territoriais que ordenem o uso do espaço levando-se em consideração a modernização dos sistemas produtivos, a conservação dos recursos naturais e a distribuição de renda e riqueza para a população do campo.

\section{REFERÊNCIAS BIBLIOGRÁFICAS}

1. Santos C dos. Níveis tecnológicos dos agroecossistemas do milho no Estado de Sergipe [dissertação]. São Cristóvão (SE): Universidade Federal de Sergipe; 2012. 144 p.

2. Cuenca MAG, Dompieri MHG, Santos FR dos. Expansão da Produção do Milho e Substituição de Cultivos na Região do Sertão Ocidental, no Estado de Sergipe. Aracaju: Embrapa Tabuleiros Costeiros; 2016. 29 p.

3. LSPA. Levantamento Sistemático da Produção Agrícola. Disponível em: <http://sidra.ibge.gov.br/home/lspa/brasil>. Acesso em: 09 de abr. de 2018.

4. USDA. World Agricultural Supply and Demand Estimates. 2018. Disponível em < https://www.usda.gov/oce/commodity/wasde/>. Acesso em: 15 de out. de 2018.

5. Galina MH et al. Análise Espaço-Temporal do cultivo de milho em Sergipe, com Auxílio de NDVI/EVI - Sensor MODIS, no Período de 2003-2012. In: Simpósio regional de geoprocessamento e sensoriamento remoto; 2014 Nov 18-21; Aracaju, SE. 103-107 p.

6. Nogueira Junior JR, Amorim JRA, Dompieri MHG. Terraceamento: Conservação do Solo e da Água no Polo de Produção de Milho, em Sergipe. Aracaju: Embrapa Tabuleiros Costeiros; 2016. 10 p.

7. Cuenca MAG, Dompieri MHG, Sá HA. Análise dos Efeitos dos Fatores de Variação do Valor Bruto da Produção de Milho por meio do Modelo Shift-Share, no Estado de Sergipe. Aracaju: Embrapa Tabuleiros Costeiros; 2015. 29 p.

8. Silva MAS, Dompieri MHG, Santos AV, Almeida MRM, Medeiros SS. Análise de Autocorrelação das Principais Atividades Agropecuárias na Área de Atuação da Embrapa Tabuleiros Costeiros. Aracaju: Embrapa Tabuleiros Costeiros; 2015. 38 p.

9. Raij BV. Avaliação da fertilidade do solo. 2.ed. Piracicaba: Instituto da Potassa \& Fosfato: Instituto Internacional da Potassa; 1983. $142 \mathrm{p}$.

10. Fritsche-Neto R, Môro GT. Escolha do cultivar é determinante e deve considerar toda informação disponível. Rev Visão Agríc. 2015;(9):12-15.

11. Almeida MRM, Galvão DMO, Batista NCS, Silva AAG, Carvalho HWL. Relatório de avaliação dos impactos das tecnologias geradas pela Embrapa. Aracaju: Embrapa, 2018. 25 p.

12. Almeida ES. Econometria Espacial Aplicada. 2. ed. Campinas: Editora Alínea; 2012. 498 p.

13. Saith W, Kamitani ELT. Convergência e dinâmica agropecuária: uma análise espacial entre os anos de 1990 e 2013. Rev Econ Agron. 2016;14(1, 2 e 3):77-104, doi: 10.25070/rea.v14i1,2,3.281

14. Rodrigues MA, Moraes ML, Bacha CJC. A expansão da cana-de-açúcar entre 1973 e 2007: uma análise espacial. In: $50^{\circ}$ Congresso da Sociedade Brasileira de Economia, Administração e Sociologia Rural; 2012 Jul 22-25; Vitória ES. 1-18 p, doi:10.2139/ssrn.2768524

15. Holler W, Mingoti R, Spadotto CA, Brasco MA. Comparação entre metodologias de representação da dinâmica territorial da produção agropecuária. Campinas: Embrapa Gestão Territorial; 2013. 39 p.

16. Garagorry FL, Silva JE, Souza MO, Chaib Filho H, Penteado Filho RC. Concentração e dinâmica de 15 produtos agroenergéticos no período de 1990 a 2006. Brasília: Embrapa Agroenergia; 2010. 191 p.

17. IBGE. Produção Agrícola Municipal. Sistema IBGE de recuperação automática, SIDRA. Disponível em: 〈https://sidra.ibge.gov.br/pesquisa/pam/tabelas $>$. Acesso em: 22 de dez. de 2017.

18. IBGE. Bases Cartográficas. Disponível em: <http://mapas.ibge.gov.br/bases-e-referenciais/basescartograficas.html>. Acesso em: 22 de dez. de 2017.

19. Neves MC, Luiz AJB. Distribuição Espacial da Cultura de Café no Estado de São Paulo. Jaguariúna: Embrapa Meio Ambiente; 2006. 23 p. 
20. Cressie N. Statistics for Spatial Data (2.ed). Londres: Wiley-Interscience; 2015.

21. Chun Y, Griffith DA. Spatial Statistics and Geostatistics: Theory and Applications for Geographic Information Science and Technology. Thousand Oaks: SAGE Publications Ltd; 2013.

22. QGIS. Versão 3.0.0. Boston: Free Software Foundation, 2018 [acesso em 12 de abr. de 2018]. Disponível em: < https://qgis.org/en/site/forusers/download.html>.

23. R Core Team. Versão 1.0.153. Vienna: R Foundation for Statistical Computing, 2018 [acesso em 18 de mai. de 2018]. Disponível em: <https://www.r-project.org/>. 